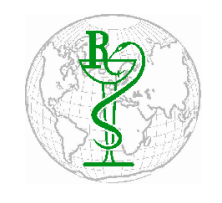

INDO GLOBAL JOURNAL OF

PHARMACEUTICAL SCIENCES

ISSN 2249- 1023

\title{
The Magic of Transformation of Stem Cells: Taught by Ancient Viral DNA
}

\author{
Shlesha Yadav, Sunakshi Koul, Rachana * \\ Department of Biotechnology, JIIT, A-10, Noida, Uttar Pradesh, India
}

Address for Correspondence: Rachana; rachana.dr@iitbombay.org

\begin{abstract}
The phenomenon of transformation has been explored to understand and treat various diseases associated with it. This potential of transformation depends upon various genetic mechanisms adapted by the genetic material of the cell. The transformation phenomenon is a special characteristic of pluripotent stem cells and is being utilize in various fields of regenerative medicine and others. There are many studies which show that, modifications of genetic material of a eukaryotic cell are accumulated during evolution and surprisingly and interestingly, the role of viruses has also been suggested to play a major role in the same. These new findings reveal that, genetic material from viruses is vital in transforming healthy human cells into pluripotent stem cells. Past research suggests that, at least $8 \%$ of the human genome is composed of these endogenous retroviruses -leftovers from retroviral infections our ancestors had millions of years ago. In the same line of research HERV-H DNA was found to be surprisingly active in human embryonic stem cells. These kind of findings would help researchers to chemically reprogram ordinary cells to become pluripotent stem cells, which could further help and lead regenerative medicine therapies of the diseases like: diabetes, stroke, multiple sclerosis, Parkinson's disease, and brain and spinal cord injury etc.. Present study describes the basics, techniques, and implications of the relation between transformation and regenerative medicine. ( 2014 iGlobal Research and Publishing Foundation. All rights reserved.
\end{abstract}

Conference Proceedings: International Conference on Life Sciences, Informatics, Food and Environment; August 29- 30, 2014

Indo Global Journal of Pharmaceutical Sciences( ISSN 22491023 ; CODEN- IGJPAI; NLM ID: 101610675) indexed and abstracted in EMBASE(Elsevier), SCIRUS(Elsevier),CABI, CAB Abstracts, Chemical Abstract Services(CAS), American Chemical Society(ACS), Index Copernicus, EBSCO, DOAJ, Google Scholar and many more. For further details, visit 